\title{
Correction to: Effect of patient positioning in axillary nerve safety during arthroscopic inferior glenohumeral ligament plication
}

\author{
Adrián Cuéllar ${ }^{1,3} \cdot$ Ricardo Cuéllar $^{1} \cdot$ Jorge Díaz Heredia $^{2} \cdot$ Asier Cuéllar $^{1} \cdot$ \\ Miguel Angel Ruiz-Ibán ${ }^{2}$
}

Published online: 16 November 2017

(C) European Society of Sports Traumatology, Knee Surgery, Arthroscopy (ESSKA) 2017

Correction to: Knee Surg Sports Traumatol Arthrosc

(2017) 25:3279-3284

https://doi.org/10.1007/s00167-016-4193-z

The author claims that his name is incorrectly listed on PubMed. The first name should be Jorge and the last name should be Díaz Heredia. On SpringerLink the name is listed correctly, but on PubMed he is listed as Heredia JD.

The original article can be found online at https://doi. org/10.1007/s00167-016-4193-z.

Adrián Cuéllar

cuellaradrian@hotmail.com

1 Department of Surgery and Radiology, University of Basque

Country, Lejona, Spain

2 Department of Traumatology and Orthopaedic Surgery,

Ramon and Cajal Hospital, Madrid, Spain

3 Department of Traumatology and Orthopaedic Surgery,

Galdakao Hospital, University of Basque Country,

c./Labeaga, s/n, 48960 Usansolo, Vizcaya, Spain 